\title{
La conexión entre los videojuegos y el fortalecimiento de la competencia lectora
}

The connection between video games and the strengthening of reading competence

\author{
Jahir Cediel Rincón ${ }^{1}$ \\ Andrea Milena Guardia Hernández ${ }^{2}$ \\ Universidad La Gran Colombia
}

Recibido: 27.08.2021

Aceptado: 30.10 .2021

\section{Resumen}

La finalidad de esta investigación consiste en dilucidar las relaciones entre el videojuego y las categorías literarias de ficción y narración, con el fin de hacer énfasis sobre las oportunidades pedagógicas que estos ofrecen respecto de la competencia lectora. Por una parte, se hizo una construcción de los esquemas conceptuales del juego, videojuego, narración y ficción para elaborar una comprensión de la estructura narrativa de un videojuego. Esa construcción conceptual permitió abordar los procesos de comprensión, específicamente de textos, y de competencia lectora, para elaborar un conjunto de criterios de aplicabilidad de un videojuego dentro del aula. Para el propósito de la investigación, se utilizó el videojuego What Remains of Edith Finch y el análisis de cada una de sus dimensiones narrativo-ficcionales. Se concluye que comprender un videojuego funciona de manera análoga a la comprensión del texto literario escrito, con el potencial añadido del videojuego respecto de su multiplicidad de

\footnotetext{
1 jcedielr@ulagrancolombia.edu.co https://orcid.org/0000-0002-6341-3000

2 andrea.guardia@ugc.edu.co https://orcid.org/0000-0002-8831-7496
}

Volumen 2. Número 2. Julio - Diciembre 2022 ISSN: 2745-0341 (En línea) 
estímulos y su constante interactividad, aspectos que podrían fortalecer una comprensión profunda y multimodal de los estudiantes. Esto confirma su potencial pedagógico, ya que el videojuego ayudaría a activar, reconfirmar y reorientar la comprensión, bien sea por sus propios objetivos, o por los aprendizajes que se propusieran dentro del aula.

Palabras clave: Juego, videojuego, literatura de ficción, análisis literario, comprensión, enseñanza multimedia.

\begin{abstract}
The purpose of this research was to elucidate the relationships between video games and the literary categories of fiction and narrative, in order to emphasise the pedagogical opportunities, they offer in terms of reading competence. Firstly, a construction of the conceptual schemes of game, video game, narrative and fiction was made to elaborate an understanding of the narrative structure of a video game. This conceptual construction made it possible to address the processes of comprehension, specifically of texts and reading competence, in order to elaborate a set of criteria for the applicability of a video game in the classroom. In this research, the video game What Remains of Edith Finch and the analysis of each of its narrative-fictional dimensions were used. It is concluded that understanding a video game works analogously to the comprehension of written literary text, with the added potential of the video game regarding its multiplicity of stimuli and its constant interactivity, aspects that could enhance students' deep and multimodal comprehension. This confirms its pedagogical potential, since the video game would help to activate, reconfirm and reorient understanding, either by its own objectives, or by the learning proposed in the classroom.
\end{abstract}

Keywords: Game, video game, fiction literature, literary analysis, comprehension, multimedia teaching. 


\section{Introducción}

Al revisar los índices de lectura se asumen cifras como las hechas por el Departamento Administrativo Nacional de Estadística de Colombia (DANE), en su Encuesta Nacional de Lectura (ENLEC), realizada en el 2017, la cual determinó que el colombiano promedio lee 2.7 libros al año, teniendo como punto de comparación a otros países del continente como Chile con 5.4, Argentina con 4.5, Brasil con 4, Perú con 3 y México con 2.7 (como se cita en Ramírez, 2020, párr. 2). Como resultado de la urgencia sanitaria mundial causada por el virus covid-19 desde finales del año 2019, y de las circunstancias asociadas como son los periodos de cuarentena y de aislamiento preventivo, la lectura de libros ha aumentado. Ya desde el periodo entre 2018 y 2019 el sector editorial colombiano aumentó en un 4.7\%, según la Cámara de Comercio del Libro (Gómez, 2021, párr. 2), lo cual aseguraría un incremento en el hábito de leer, sea cual fuera el ámbito. Esto se corroboraría con lo dicho por Ávila para Revista Semana: "la pandemia ha sido una oportunidad para aumentar las ventas online de las librerías (...) Solo para marzo del año pasado, las librerías que tenían este servicio electrónico crecieron hasta un 300\%" (2021, párr. 15). Aunque el panorama pudiera parecer alentador por el aumento de la lectura en el país, podrían anticiparse dos problemas: 1. Aunque los índices de lectura aumenten, no significa que las estadísticas que tengamos hoy en día cumplan las expectativas generales; los índices de lectura, sobretodo ficcional, siempre son mejorables. Y 2. Las estadísticas sobre los índices de lectura, por no tener una base cualitativa, caerían en el error de mostrar resultados como procedimientos; comprar un libro o tener la pantalla de la tablet encendida por cierta cantidad de tiempo no significa necesariamente haber leído y, especialmente, haber comprendido. No obstante, las cifras de la ENLEC no explicitan los procesos cognitivos y afectivos de la lectura; se estaría igualando la oferta y demanda de libros con su lectura. Ciertamente estos índices pueden tener su complemento efectivo en los resultados de la prueba Saber de 2019-II (Instituto Colombiano para la Evaluación de la Educación [ICFES], 2020, p.30), donde se aclara que el 49\% de los estudiantes que realizaron la prueba de lectura crítica estuvieron en un nivel satisfactorio (3 de 4) mientras que el 34\% se encuentran en un nivel regular (2 de 4). Como también en los resultados de las pruebas PISA del año 2018 (Organización para la Cooperación y el Desarrollo Económicos [OECD], 
2019, p.2), donde se especifica que el 50\% de los estudiantes alcanza un nivel medio de lectura (2 de 6), frente a la media establecida por la OECD de 77\%; estos estudiantes pueden extraer información explícita de textos con extensión moderada, así como encontrar un posible propósito al texto leído, siempre y cuando se les instruya para ello. Por lo que es importante no solo leer más, sino también mejor.

Habría que recordar que la lectura es un proceso e implicación humana fundamental. Leer una ficción es una pausa crítica a la vida cotidiana, por lo que quien lee no solo está encontrando un sentido restringido al soporte de lectura, sino también encuentra en aquello que lee su relación con el mundo. La lectura ficcional sitúa al hombre en tiempos y espacios distintos, por contraste de la lectura y la vida real, que podrían ampliar el horizonte de comprensión del mundo de la vida; en otras palabras, la creación del sentido a partir de la lectura podría situar críticamente al hombre en un contexto determinado. Aunado a la creación del sentido, estarán todos los procesos secundarios que actúan en referencia a la lectura: la memoria, la atención, la percepción o la posibilidad de leer de forma explícita e implícita. En este orden de ideas, la lectura no solo otorga un sentido interior o exterior al propio acto, sino que ayuda a fortalecer competencias de lectura que podrían ser utilizadas con otros fenómenos de la realidad, abriendo la posibilidad de la lectura multimedial o multimodal, en el marco de las nuevas literacidades.

Esta multimodalidad, entendida como la multiplicidad de recursos discursivos que utiliza un soporte para transmitir sus implicaciones, como pudiera suceder con los videojuegos con los estímulos sonoros, visuales o kinestésicos, etc., podría ayudar a aumentar las estadísticas del fenómeno de lectura en Colombia. Según la empresa de investigación y Big Data Sinnetic, la cantidad de videojugadores en el país aumentó casi un 17\% para marzo del 2020, pasando de 1.8 millones a 2.1 millones. Esta alza pudo deberse a la pandemia o, también, al aumento de celulares inteligentes en el país, pues este dispositivo es uno de los principales puntos de acceso a los videojuegos; "69.1\% de los adultos colombianos juega en su celular", según muestra el estudio de la empresa de publicidad Adsmovil (como se citó en Vargas, 2020, párr. 5). 
El uso y acceso de los videojuegos en los tiempos actuales va en aumento, por lo que internarse en algunas categorías que lo expliquen puede ayudar a aplicarlo por su potencial para el fortalecimiento de la lectura multimodal. Habría dos puntos de fuga: por un lado, la pretensión de querer aumentar las estadísticas de lectura de ficción, y por otro, querer comprobar que la lectura se efectúa realmente. Para ello, tenemos que el fenómeno de los videojuegos tiene un gran potencial estadístico, que sirve como una apertura para su aplicación, y por otro, la educación como forma de estructurar guías y lineamientos, con los cuales poder comprobar que la lectura se realiza en términos de competencia lectora.

\section{Acercamiento conceptual al videojuego narrativo-ficcional y la comprensión lectora}

La presente investigación centra sus inmediaciones conceptuales y conclusiones en la búsqueda bibliográfica de las categorías de ficción, narración, videojuego y comprensión lectora para resaltar su relación, con el fin de elaborar un cuerpo conceptual que pudiera llegar a sustentar rutas o enfoques didácticos para el aula de clase. Por lo que, los alcances conceptuales del presente documento se restringirían a la indagación bibliográfica sobre la relación entre el videojuego y la narración/ficcional dentro de la comprensión lectora. En este sentido, las conclusiones se alimentarían de esta relación conceptual sin incluir una aplicación en un contexto en concreto.

Para llegar a abordar el videojuego como una posibilidad para fortalecer la competencia lectora se hace necesario delimitar un esquema conceptual que permita acercarlo a las estructuras narrativas compartidas con los textos de ficción. Para ello, se parte de la comprensión de la narración como una mediación lingüística entre el mundo real y el hombre, una traducción de la multiplicidad ininteligible del mundo a un orden simbólico concreto. Esta traducción derivaría necesariamente en una triada: primero estaría la traducción por sí misma, o sea la narración; luego el traductor, o narrador; y por último un lector. Este lector sería el último filtro para la existencia de la narración, pues no habría una traducción del mundo en forma de lenguaje sin un receptor quien la recree, puesto que "la referencialidad distinta de la 
expresión no reside, pues, en la expresión misma, sino en quién la recibe” (Eco, 1962, p.102). En principio, todo texto narrativo está en cierto modo incompleto, como afirma Eco, "todo texto es una máquina perezosa que le pide al lector que le haga parte de su trabajo" (1994, p.11). Por lo que una narración no sería tal sin un lector cocreador que abra con su lectura la posibilidad de un hallazgo de "nuevos significados e identificaciones existenciales" (Contursi y Ferro, 2000, p.59). La narración es un proceso de búsqueda de un sentido, pudiera ser al interior o exterior del texto, por medio de un cierto interés que la misma narración despierte en el receptor, ya que "un texto narrativo debe poseer como referente un suceso o una acción que cumplan con el criterio de suscitar el interés" (Contursi y Ferro, 2000, p.30).

Ahora bien, el texto narrativo tiene la capacidad de despersonalizar a su lector, lo que Umberto Eco llama pacto ficcional. Esta implicación sobre la identidad del sujeto se da cuando la narración establece un mundo posible que tiene su propio fundamento fuera de una cotejación con el mundo real, porque "la ficción no solicita ser creída en tanto que verdad, sino en tanto que ficción” (Saer, 1997, p.12). No obstante, la ficción tiene una partida del mundo real, Eco afirma que "también el mundo más imposible, para ser tal, tiene que tener como fondo lo que es posible en el mundo real" (1994, p.92). En este sentido, el texto narrativo establece su propio código, o CRI (Campo de Referencia Interna), definido por Harshaw como "toda una red de referentes interrelacionados de diversos tipos: personajes, acontecimientos, situaciones, ideas, diálogos, etc.” (1984, p.127). El lector/jugador se encontraría con un videojuego que se determina por las experiencias que este pudiera ofrecer, por la capacidad de mantener al usuario in-game (Koenitz, 2018, p.4). Todo lo que suceda en la narración ficcional tiene sus bases en el CRI, por lo que el papel del lector es aceptar tácitamente este universo simbólico alternativo; no se leería completamente una narración si a cada paso se intenta comprobar la veracidad de los hechos con los métodos del mundo real. Del mismo modo en que no hay que comprobar la ficción, esta no puede presentar inconsistencias ya que "los mundos que implican contradicciones son imposibles, impensables, «vacíos»” (Dolezel, 1988, p.81). El código que establece la narrativa ficcional es taxativamente despersonalizante, pues exige al lector salir de su lugar real para aceptar el funcionamiento del mundo ficcional, mundo posible que, como un juego, tiene sus propias reglas que deben ser aceptadas para poder participar en 
él. Esta despersonalización ficcional tiene vías infinitas por medio de la narrativa; si todo es posible en un mundo ficcional entonces habría distintas problematizaciones y tipos de resoluciones. Es gracias a la ficción que la narración puede hablar sobre intersticios de la vida real, con premisas implícitas como ¿Qué pasaría si...?. El establecimiento del código narrativo que despersonaliza ficcionalmente conlleva a que haya un contrato literario entre el hecho narrado, el narrador y el lector. Y esto podría dirigir a una suspensión crítica de la realidad, ya que:

Tanto P. Ricoeur (1983-1985) como W. 1ser (1990) o M. Vargas Llosa (1990: 5-20) coinciden en señalar que la ficción permite al hombre profundizar en el conocimiento de sí mismo, alcanzar sus anhelos, evadirse de las circunstancias que condicionan su vida cotidiana y tener acceso a experiencias del todo imposibles por otros conductos'. (Garrido, 1997, p.38)

Por otra parte, las narraciones deben contener una oposición del estado natural o inicial, una problematización de los hechos primigenios, lo que Contursi y Ferro (2000, p.30) llaman complicación, la cual establece un puente o punto de interés entre la obra narrativa, que es estática, y el lector, quien cambia en el transcurso del tiempo. Esta oposición puede tender a una resolución buena o mala para los personajes en cuestión, y de allí depende ese involucramiento del lector, porque sería él quien delimita lo bueno y/o malo de esa resolución.

La complicación en una narración puede establecerse al inicio, a la mitad o al final, su consecuencia, en el lector, es suscitar el interés, hay que tener en cuenta que:

Las narraciones suelen comenzar enunciando o identificando algún problema que se haya presentado en el transcurso de la habitualidad. Ya sea porque lo que se venía haciendo no resulta, porque se plantea una situación imprevista, o bien una demanda inesperada, lo cierto es que hay algo diferente que desafía y promueve formas de acción alternativas. (Alliaud, 2006, p.13) 
Ahora bien, esta puesta en tensión de la narración, la cual desarrolla narrativamente el mundo ficcional y que podría suscitar el interés del lector, también responde a un tipo de ordenamiento de eventos en forma consecutiva según los lineamientos y preconcepciones que establece el narrador en su narración. Es decir "en la historia, varios acontecimientos pueden desarrollarse al mismo tiempo; pero el discurso debe obligatoriamente ponerlos uno tras otro; una figura compleja se ve proyectada sobre una línea recta" (Todorov, 1970, p.174). De manera que analizar la forma de la narración también permite entrever su contenido, de modo que la trama, esto es, el uso de los mecanismos discursivos, y la fábula, lo contado en sí mismo, se entrecruzan en la narración. En otras palabras, la trama no puede actuar de forma independiente de la fábula, o también, la forma de contar una narración hace necesario un contenido narrado, no habría qué sin un cómo.

Todorov (1970, pp.159 - 161) habla de las repeticiones que el discurso establece para dar cuenta de la narración, como lo son las reincidencias sobre eventos, personajes o descripciones que median la experiencia del lector con la narración, de manera que el discurso variaría cada reincidencia de forma particular en cada relato, para que este sea diferente de otros. En este sentido, "todos los relatos del mundo estarían constituidos (...) por diferentes combinaciones de una decena de micro-relatos de estructura estable, que corresponderían a un pequeño número de situaciones esenciales de la vida: podríamos distinguirlos con términos como “engaño", “contrato”, “protección”, etc.” (Todorov, 1970, p.161). Es decir, hay distintos conceptos, sentimientos o pensamientos que unen la narración a sus implicaciones y su importancia es mayúscula porque, como afirma Todorov, no son los hechos y los personajes referidos lo que importa para la narración, sino la manera, el modo, en que el narrador los pone en conocimiento del destinatario (1970, p.41). La narración y sus variaciones de posibles iteraciones se establecerán en las características propias de un concepto, en tanto se retrase, se prolongue o nazca de una acción mayor. Este panorama narrativo que influye sobre la ficción abre la posibilidad de un complemento a la vida del ser humano, ya que le ofrece a este una pausa que, difícilmente, otra dimensión podría igualar. 
La trama del videojuego utilizaría también estos distintos recursos discursivos para adentrar al jugador a su submundo narrativo, a su fábula. Vale la pena aclarar que el videojuego trata cada categoría de la trama de distintos modos, o lo que es lo mismo la lectura multimodal, para dar a conocer su contenido, de allí que la experiencia narrativa del videojuego dependa de sus propias implicaciones narrativo-ficcionales. El videojuego comparte estas dimensiones ya que en el juego "las leyes y los usos de la vida ordinaria no tienen validez alguna. Nosotros "somos" otra cosa y "hacemos otras cosas"” (Huizinga, 1938, p.26). En este sentido, el juego también despersonaliza al receptor por su ficción, por lo que el juego podría entenderse como una suspensión crítica de la existencia cotidiana. El videojuego también da una posibilidad infinita a la narración por medio de su ficción, ya que entiende los objetos dentro de contextos semánticos concretos, en otras palabras, el objeto en el videojuego es una simulación de algo en particular (Fabricatore, 2000, p.5). De manera que el contexto del mundo posible configura la función de sus propias inmediaciones. En este orden de ideas, el videojuego es una suspensión nada más porque no sería juego propiamente dicho si se extendiera hasta límites desconocidos, siempre debemos volver a ser nosotros. Esta cierta libertad que ofrece el juego se acota no solo por sus propias implicaciones, sus reglas, sino también por el modo, espacio o mecanismo por el cual se muestre, es decir, por su propuesta de mediaciones posibles. Esta proyección audiovisual tiene sus propias implicaciones para el videojuego, ya que necesariamente el videojuego debe tomarse como una simulación (Frasca, 2009, p.6), como una forma de controlar objetos simulados que no están en la vida real, de manera que el videojuego re-crea un espacio y tiempo distintos de la cotidianidad, crea mundos posibles de ficción.

Puesto que el videojuego parte de una simulación, entonces valdría la pena hablar sobre mecanismos de inmersión a dicha simulación. Uno de ellos podría ser la interactividad constante del usuario con el videojuego, una retroalimentación visual, kinestésica o sonora, de modo que el videojuego reconfirma constantemente las acciones del jugador en la pantalla. Cabañes habla del videojuego como un medio tecnológico-sensorial (2012, p.67), lo cual puede ayudar a entender este medio no solo como una entretención, sino como un mecanismo interactivo que pudiera tener distintos puntos de fuga a distintas áreas. Por ejemplo, son

Volumen 2. Número 2. Julio - Diciembre 2022 
comunes los videojuegos aplicados a la medicina, la psicología o la arquitectura por lo que el videojuego es un conjunto de archivos con lenguaje de programación que tienen la capacidad de repercutir en las sensaciones, y quizá, en los sentimientos de quien juega. Hay videojuegos que transmiten emociones y pensamientos por medio de sus implicaciones discursivas, donde hay un traspaso simbólico entre aquello que ocurre en el videojuego y el jugador como receptor de su particular lectura. Un traspaso que también podría entenderse como un proceso de traducción del soporte del videojuego al mundo del jugador. En medio de ambas perspectivas y puntos de fuga existirían dos actividades de traducción: la actividad diegética y extradiegética, definidas por Wolf y Perron (2005, p.18) como los movimientos del avatar del jugador en pantalla y las acciones que desempeña el jugador en la vida real para lograr la actividad en pantalla, respectivamente. Un medio interactivo que notifica a su jugador su actividad en pantalla, en un proceso de retroalimentación constante (Fabricatore, 2000, p.10). Una retroalimentación que se vería complementada por las dimensiones del videojuego.

Las categorías propuestas por Aarseth se han consolidado en la bibliografía especializada como la base conceptual para entender el videojuego, las cuales sirven de base para comprender el funcionamiento de la traducción que hace el jugador. Estas son gameplay, gamestructure y gameworld, las cuales son traducidas y resumidas por López (2013, p.41) de la siguiente manera. En primer lugar, el gameplay puede ser entendido como un modo de jugar y describe las motivaciones del jugador a jugar de cierta forma o perspectiva; de allí que haya una serie de estrategias o acciones que este tome en relación al videojuego. En segundo lugar, el gamestructure podría ser entendido como las reglas del juego, lo que delimita internamente cómo se gana y cómo se pierde, así como el qué hacer y cómo proceder dentro del videojuego; esta dimensión es la que le da cierta libertad al jugador, pues de las limitaciones nace la particular libertad. Finalmente, el gameworld, es definido como el universo del videojuego, es decir, todos los escenarios, personajes, barras de energía, mensajes, sonidos, etc.

El gameworld puede ser entendido como un universo explorativo, experiencial y potencial por cuanto un videojuego no muestra completamente sus inmediaciones y es el jugador quien las descubre en el transcurso de su experiencia mediada por el gamestructure en el gameplay. 
Esta capacidad explorativa del jugador en el videojuego tiene sus matices internos, en cuanto a tipos de juego y comportamientos requeridos del jugador. En este sentido podría decirse que el videojuego configura a su usuario, porque le impone un conjunto de comportamientos y acciones a realizar. El gamestructure impone unos objetivos o metas al jugador en el videojuego, ir a determinado lugar, atrapar al ladrón, perseguir al helicóptero, etc., de modo que el videojuego siempre está proponiéndole al jugador que interactúe en su gameworld con un gameplay determinado. Esta meta a la que hay que llegar necesariamente hace que el jugador tenga una experiencia narrativa determinada y única; tal como ocurre en la vida real, dirigirse a un cierto lugar implica unas condiciones narrativas específicas.

Estos elementos del videojuego estarían al servicio de la narrativa ficcional y de la experiencia narrativa del jugador. Esta experiencia podría tener dos dimensiones, que se pueden llegar a fundir entre sí: por un lado, hay videojuegos con narrativas ficcionales claras, como Super Mario Bros 1 o Hollow Night, las cuales delimitan un poco más la experiencia narrativa del jugador; por otro lado, hay videojuegos sin narrativas ficcionales claras, como Pacman, Bomberman o Rocket Leage, los cuales podrían hacer surgir narrativas imaginadas al jugador. En el caso del primer tipo de videojuego, estos usarían todas sus limitaciones internas y externas, sus reglas de juego y sus limitaciones de soporte, respectivamente, para transmitir una historia. La vibración del mando, los mensajes en pantalla o la atmósfera musical pueden dar luces sobre qué está ocurriendo en la narrativa ficcional del videojuego (Manovich, 2001, p.43, citado por Wolf y Perron, 2005, p.20).

Al respecto, Ruiz (2013) dice algo interesante sobre los videojuegos y las narraciones

En nuestras sociedades existen dos tipos de construcciones culturales fundamentales diseñadas para obtener vivencias narrativas: los relatos y los juegos (...) Solo se vive de forma narrativa cuando esta vida se interpreta como una historia en la mente de alguien. Si esta interpretación se explicita en un texto, oral o escrito, entonces ya se ha construido un relato. (pp.22-24) 
Narrativa y videojuego estarían íntimamente ligados en su propensión a la ficción; jugar implica sumergirse en un mundo posible con un determinado número de reglas que, tajantemente, deben ser respetadas para poder jugar. De modo que el pacto ficcional también lo establece el videojuego con su jugador durante los primeros minutos, en forma de introducción o tutorial. En esta fase, el propio videojuego explica sus condiciones narrativoficcionales, además de las limitaciones de su gamestructure y gameworld, que determinan el gameplay, es decir, el videojuego configura a su jugador, con todos sus comportamientos permitidos. Y de allí surgirían los tipos de videojuegos.

El videojuego también se permite experimentar con el tiempo y el espacio, deformándolo para sus propios intereses discursivos (Ruiz, 2013, p.31). Tanto la narrativa como el videojuego con una historia explícita "están encapsulados y separados respecto al fluir continuo y difuso de la vida cotidiana" (Ruiz, 2013, p.31). El videojuego, al igual que la narrativa, contiene la ficción, porque ambos tienen la capacidad de suspender el tiempo de la vida real y plantear mundos que tienen como base el mundo cotidiano. A partir de las anteriores afirmaciones se puede inferir que la experiencia con el videojuego permite la creación de sentidos múltiples, donde la identificación del jugador con el videojuego permite que esta ficción narrativa pueda ser re-creada, dando como resultado una experiencia en el juego que se complementa con la de la vida real. Los videojuegos "son, por tanto, poderosos instrumentos con los que los usuarios aprenden a situar significados, a construirlos, a través de la experiencia" (Aranda y Sánchez, 2009, p.13).

La experiencia del lector/jugador/receptor narrativo-ficcional se abriría a la comprensión lectora en medio de ese tejido entre ficción, narración y videojuego y puede potenciar el trabajo en aula abordando procesos como el recuerdo, la re-narración y las hipótesis sobre aquello que se lee multimodalmente. Para acercarse a este ejercicio, es interesante iniciar la observación de la competencia lectora a partir de una dimensión más amplia como es el proceso básico de comprensión. Ya en la filosofía podríamos hablar de un sujeto que entiende a partir de la historia que le acontece; la historia sería un transcurso entre el pasado, presente y futuro que se conectan en el fundamento de comprender. De manera que los objetos 
cognoscibles pueden ser el resultado de la historia que rodea tanto al receptor como al objeto en sí. En psicología, la comprensión parte de unas bases similares, al situar al hombre como resultado de sus esquemas de comprensión, unos "bloques básicos de construcción del pensamiento" (Woolfolk, 2010,p.60) que se articulan a la realidad de forma en que esta pueda ser conocida a partir de lo que ya sabemos. El conocimiento del futuro se vuelve más o menos tangible a partir de las hipótesis que tenemos gracias al pasado. Es a partir de los esquemas de comprensión que el hombre se sitúa en el mundo como sujeto entre otros, por lo que comprender no es la finalidad de un proceso, sino que es precisamente ese proceso.

Siguiendo esta premisa, se entiende mejor el hecho de que Umberto Eco hable de una obra abierta como una apertura a la interpretación constante de un objeto estético (1962, p.35) de manera que la obra no se sitúa como un objeto inmóvil en el tiempo, sino que es dinámica debido a sus posibles interpretaciones. En este sentido, podría decirse que no solo los objetos estéticos de los que habla Eco pueden estar abiertos gracias al devenir del tiempo, la realidad también se encuentra en el punto medio de la indeterminación del presente, en una dialéctica del desconocimiento. Nunca sabremos de forma exacta qué depara el futuro. Aplicamos lo que sabemos a lo que no, en un ciclo que podría llegar a ser eterno en términos de la comprensión. Análogamente, y quizá por ello, Eco habla un texto perezoso que le pide a su lector que haga parte de su trabajo de forma constante (1994, p.11).

La constante interpretación de una obra tiene como antecedente los esquemas de comprensión del individuo, los cuales podrían complementarse en tres dimensiones específicas: la memoria, la atención y la percepción. La memoria podría ser definida como "la facultad por medio de la cual se retiene y recuerda el pasado (...) por la cual se almacena el conocimiento que se tiene sobre algo y las interpretaciones que se hacen de ello" (Fuenmayor y Villasmil, 2008, p.193). Del mismo modo, la atención es una disposición de los estímulos, porque "al poner atención para seleccionar unos estímulos e ignorar otros, limitamos las posibilidades de lo que percibimos y procesamos. Aquello hacia lo que dirigimos nuestra atención depende, en cierto grado, de lo que ya sabemos y de lo que necesitamos saber" (Woolfolk, 2010, p.239). Por último, la percepción podría ser definida como la cualidad semántica del hombre en el 
mundo, ya que al estímulo que se le atribuye un significado se le denomina percepción y en sus bases estarían tanto "las representaciones físicas del mundo como (...) el conocimiento que poseemos" del mismo (Woolfolk, 2010, p.66). Este conjunto de subprocesos que prefiguran y configuran los esquemas mentales se combinan en la práctica. Casi que es indisoluble el hecho de que mientras se pone atención se está atribuyendo un significado por medio de la memoria. A partir de ello, se puede hablar de un videojuego como medio interactivo que reclama la atención constante de su usuario; aquellos elementos del gameworld como los recursos visuales, sonoros o kinestésicos reconfirmarían las acciones del jugador. De este modo, la experiencia narrativa del jugador en el videojuego necesitaría de los procesos de memoria para poder avanzar a través del gameworld delimitado en el gamestructure y del gameplay propuesto por cada jugador.

Además, esta triada de comprensión tiene una aplicación particular en el marco de los objetivos de lectura, los cuales se entienden como un tipo de ordenamiento que podría darse por un solo pensamiento con el potencial de activar un esquema de comprensión determinado para la actividad lectora (Solé, 1992, pp.34-35; Eco, 1987, p.50). Valdría la pena acotar que el objetivo de lectura puede ser una imposición hecha por el gamestructure del videojuego, y/o por el jugador en su propia experiencia. Por ello, si el jugador quiere resaltar a un personaje en particular, entonces sus acciones, espacios y características se van a priorizar, en lugar quizá de las situaciones o momentos donde este no se encuentre y donde al final se sepa que no hubo relevancia narrativa. Un objetivo de lectura direcciona la disposición, es decir, la atención, la percepción y la memoria hacia un punto o puntos específicos del videojuego. Por tanto, un objetivo de lectura puede volver significativo lo insignificante y visible lo invisiblemente sugerido, funcionando como un prisma lector. De manera que un objetivo de lectura, cuyos procesos internos estarían dirigidos por la memoria, la atención y la percepción en esquemas de comprensión concretos, mediarían la experiencia del jugador con el videojuego. El objetivo de lectura puede ser la piedra angular de las proposiciones y disposiciones que se hagan del videojuego dentro del aula en tanto que competencia lectora. Es decir, gracias al objetivo de lectura el estudiante podrá dirigir su lectura a una meta que el videojuego o el docente propusieran dentro del aula. Dadas las particularidades del videojuego

Volumen 2. Número 2. Julio - Diciembre 2022 
en materia narrativo/ficcional, podría fortalecerse la competencia lectora de forma controlada para las propias inmediaciones del videojuego, el objetivo de lectura y la lectura del estudiante dentro del aula de clase.

\section{2. "What Remains of Edith Finch"}

Con el fin de explorar los alcances de una propuesta pedagógica para fortalecer la comprensión de lectura a partir de la base conceptual esbozada, esta investigación abordó el videojuego What Remains of Edith Finch, creado en el 2017 por el equipo independiente de videojuegos Giant Sparrow, publicado por la distribuidora Annapurna Interactive y disponible para Microsoft Windows, Play Station 4, Nintendo Switch y Xbox One. What Remains of Edith Finch es un videojuego que tiende a priorizar la narrativa ficcional sobre un conjunto de mecánicas comunes en otros videojuegos como lo pueden ser saltar, combatir, rodar por el suelo, etc.

La historia involucra al jugador en la familia Finch y su maldición, la cual mata a todos sus integrantes de formas extrañas. Por medio de Edith Finch, la última superviviente de la familia, el jugador se adentrará en la historia de cada uno de los integrantes del hogar. Una madre que ocultó secretos en la antigua casa y una hija que quiere desentrañar todos sus misterios son los motores principales de la narrativa. Este es un videojuego que tiene como fin la comprensión de una historia y todos sus intersticios velados por el tiempo.

En el momento de analizar What Remains of Edith Finch se propuso un conjunto de categorías que permiten organizar su estructura. En este sentido, el CRI ofrece incidencias narrativoficcionales del videojuego, como son, en primer lugar, los distintos avatares o personajes que identifican al jugador en pantalla y que son fundamentales, al punto en que pocos videojuegos no los incorporan. El avatar es tan importante como la narrativa, porque debe haber un quién en medio del qué y el cómo discursivos. Luego, habría que centrar la atención en la historia misma, esto es, en el transcurso de los eventos en el tiempo que constituyen la narrativa ficcional del videojuego. En los eventos que suceden en el videojuego podríamos hablar de 
un estado inicial, o primigenio, que establece la normalización para los personajes; luego de una ruptura de esa normalidad, una problematización, o problematizaciones, de esos hechos primigenios; por último, la resolución, o resoluciones de esas puestas en tensión. En ocasiones, esta resolución puede ser buena para los personajes en cuestión, como puede que no, dependerá en gran medida de las incidencias de la problematización narrativa. Por último, dentro del Campo de Referencia Interna, tendríamos las situaciones reincidentes, o repeticiones narrativas, aquellos conceptos que vuelven una y otra vez sobre los personajes en su viaje o transcurso narrativo. Así, el acercamiento a un videojuego parte del CRI, que se subdivide en tres: personajes, eventos y repeticiones; por su parte, la categoría de eventos se dividiría en tres: estado inicial, problematización(es) y resolución(es).

En el caso concreto de What Remains of Edith Finch los personajes tienen cada una historia particular que se entrelaza de un modo u otro con las demás, por lo que cada avatar tiene un sub-bloque de la historia general (el hijo de Edith, Edith, Molly, Odin, Calvin, Bárbara, Walter, Sam, Gregory, Gus, Milton, Lewis y Edie). Por lo tanto, hablar de los eventos del videojuego supondría explicitar las relaciones de causa y efecto iniciales, problematizantes y resolutivas de cada bloque de personaje. De forma amplia, podríamos hablar de estados iniciales extraños por sí mismos, matizados por una peculiar normalidad. Por ejemplo: el estado inicial del hijo de Edith es en un barco que abandona una isla, dirigiéndose a un paraje desconocido; el de Odin muestra que el personaje estuvo enterrando a su esposa e hijo recién nacido, muertes provocadas por la maldición familiar; o el de Sam, que muestra cómo el personaje va de caza con su hija, etc. Del mismo modo, las problematizaciones que el videojuego propone tienen la premisa de la muerte o la desaparición. Por ejemplo, en Edith, cuya ruptura con la realidad es notar que cada miembro de su familia ha muerto de forma inusual, y ahora ella, la última superviviente, intenta averiguar qué sucedió en cada caso; en Calvin esa ruptura es la pérdida del control en un columpio; o en Milton, quien pintaba un pintor que estornudaba sobre otro. Finalmente, cada resolución presenta una conclusión sobre esa muerte o desaparición de la problematización. Por ejemplo, en Molly, quien se convierte en una serpiente quien devora a la protagonista en su forma humana; en Bárbara con su 
asesinato a manos de asesinos locales; o en Gus, quien es asesinado por una tienda de campaña que lo aplasta, producto del ímpetu de una gran tormenta.

Debido al entrecruzamiento de las historias de cada personaje, el videojuego contiene eventos discursivos que son repetidos por la instancia narrativa, así como hay reincidencias generales, es decir, aquellas que se presentan en toda la obra. Estas repeticiones implican por parte del jugador habilidades como leer textualmente para entender la mayor parte de la historia; tener que encontrar la forma de ingresar a la habitación detrás de cada puerta sellada o mirar por la mirilla de cada una; como también, la reincidencia sobre la muerte de cada uno de los personajes en cuestión.

Acercarse al videojuego desde estas categorías permiten representar parte del universo narrativo-ficcional del videojuego, de manera que se hace evidente cómo cada personaje tiene su modo particular de abordar la realidad que le corresponde, con referencias a otras historias del apellido Finch. Este conjunto de historias, unidas por el hilo argumental y narrativo de Edith, construyen una antología que aporta, de un modo u otro, a la comprensión de la tensión general del videojuego: la maldición que mata de forma extraña a cada uno de los miembros de la familia.

\section{What Remains of Edith Finch como propuesta pedagógica para el fortalecimiento de la competencia lectora, direcciones de aplicación}

El análisis de estas dimensiones narrativas y ficcionales de un videojuego permite aproximar una propuesta educativa frente al fortalecimiento de los procesos de lectura, ya que, si hay conocimiento de la narrativa ficcional del videojuego, en algunas de sus particularidades, entonces podrían plantearse objetivos de lectura que dirijan a estas inmediaciones. Las unidades didácticas en lenguaje podrían organizarse para, por ejemplo, ir comprobando, un paso a la vez, cada una de las dimensiones del videojuego, por lo que leer multimodalmente se convertiría en un proceso controlado y dirigido a ciertos objetivos de lectura, los que podrían compatibilizar conceptualmente con los aprendizajes del aula. Tal como debe haber 
una meta a la cual llegar en el videojuego y un aprendizaje propuesto en el aula de clase, debe haber un objetivo de lectura que pudiera conciliar o familiarizar ambos espacios. Habría que recordar que este objetivo de lectura tendría como antecedente la memoria, atención y percepción de los esquemas de comprensión, por lo que las preguntas como eje de reflexión pueden ser transversales a los esquemas de comprensión porque estarían dirigidas a un objetivo de lectura en concreto. Las preguntas "estimulan los niveles más altos del pensamiento [y] promueven el aprendizaje, ya que requieren que el estudiante aplique, analice, sintetice y evalúe la información en vez de recordar hechos" (Redfield y Rousseau, 1981; Andre, 1979 y Gall, 1970, como se citó en Fundación Promigas, 2013, p.44). Una buena pregunta, hecha en el momento indicado puede escindir el pensamiento, ser la separación entre aquello que se quiere aprender y lo que no. Las preguntas ayudarían a asegurar la atención, percepción y memoria a un objetivo claro, de manera que la duda sería la principal herramienta de la creación del sentido propuesto. En última instancia, siempre una interrogante nos hace volver sobre nuestros pasos para determinar aquello que dejamos en el aire.

Para el desarrollo de las clases podrían establecerse dos tipos de objetivos de lectura que restrinjan el videojuego a unas cuantas dimensiones. Uno podría ser sobre un objetivo que el mismo videojuego proponga y otro que sea propuesto al interior del aula; tanto el uno como el otro se dirigirían al videojuego propiamente y planearían descubrir algo a partir de sus inmediaciones narrativo-ficcionales, de modo que el jugador encontraría una mediación narrativo-ficcional dirigida y controlada.

Para la formulación de preguntas particulares a momentos específicos del videojuego, que tengan como fin su comprobación de lectura en un objetivo de lectura, habría que entender las implicaciones conceptuales de las categorías desde las cuales se planteen, en otras palabras, habría que entender qué implica un estado inicial, problematización, resolución, etc., para que la pregunta sea efectiva. Para la categoría de personajes, por ejemplo, podría indicársele al estudiante que recuerde a algún personaje y/o su función narrativa, o que reflexione e hipotetice sobre aquellos que aún no aparecen. Para los estados iniciales podrían establecerse preguntas en torno a lo sucedido en esa sección, es decir, interrogantes que busquen re-narrar 
lo ocurrido en ese sub-bloque narrativo, o también, formular preguntas sobre las relaciones de causa-efecto sobre el estado inicial. Para las problematizaciones podría ser valioso preguntar sobre las implicaciones de esa ruptura con la normalidad; sobre la relación que tenga esa problematización con otras zonas del videojuego, o también sobre la realidad y una situación particularmente similar. Para la resolución podría preguntarse sobre lo ocurrido en el bloque de historia determinado, o quizá, problematizarse la resolución por sí misma, es decir, indagar si esa resolución no es tan solo otro tipo de problematización o estado inicial. Por otro lado, para las reincidencias narrativas podría preguntarse sobre el orden y disposición de cada una de las repeticiones discursivas, intentando dilucidar su sentido discursivo.

A partir de cada objetivo, las distintas categorías de análisis (personajes, eventos, repeticiones, etc.) podrían proponerse pragmáticamente en forma de preguntas que conlleven a ese objetivo por medio de la creación concreta de sentido bajo los esquemas de comprensión adecuados. Si tuviéramos en cuenta el objetivo que propone el videojuego, es este caso, abrir las puertas del hogar en la primera parte, y partiendo de la categoría de los personajes, podríamos preguntar al estudiante cuáles serían los personajes, cuáles serían las puertas que aún faltan por abrir, cuáles han sido los personajes mencionados hasta el momento o qué relación tendrían los personajes que han aparecido con los espacios a los que no se tiene acceso. En este mismo sentido, podrían dirigirse los eventos del videojuego a este objetivo, de manera que en el estado inicial podría preguntársele al estudiante por qué cree que a Edith no le permitían entrar a todas las habitaciones de la casa Finch. En términos de la problematización podríamos preguntar, luego de cierto tiempo, de dónde podría venir la maldición de la familia Finch o qué podría esta representar. También podríamos problematizar el videojuego desde su exterior y no tanto desde sus propias inmediaciones narrativas, pero aún en miras del objetivo de lectura; por ejemplo: ¿podría ser la maldición de los Finch una patología generacional? La resolución podría problematizarse con dudas como: ¿cuál podría ser la relación entre cierto personaje con otro? o ¿por qué cree que esa relación de causa-efecto se dio de tal manera y no de otra? Ahora bien, para las reincidencias narrativas podría preguntársele al estudiante: ¿qué elementos, que considere importantes, habría en cada una de 
las habitaciones vistas desde la mirilla de cada puerta?; o, quizá, ¿por qué cree que la narración ha reincidido sobre ciertos personajes y no otros?

Por otra parte, el objetivo de lectura podría ser propuesto por el docente y, por ejemplo, podría centrarse la atención en un personaje específico. En el caso de Milton, las preguntas se dirigirían a la caracterización del personaje, denotando la mayor parte posible de su interioridad. En este orden de ideas, podría preguntársele al estudiante por qué cree que el personaje Milton no es jugable; o, quizá, si hay casos en Noruega de desaparición de jóvenes artistas relacionadas con extrañas maldiciones familiares. En cuanto al estado inicial del personaje podría preguntarse qué relación tendrían los dibujos hechos por Milton con la vida de este. Mientras que para la problematización podría preguntarse de qué otro modo podría cambiarse la ruptura con la normalidad hecha por el videojuego. Y para la resolución quizá podría interrogarse lo que sucedió en la historia de Milton; qué podría representar que la historia de Milton, tanto en su inicio, problematización y resolución, no tenga diálogo alguno; o, también, por qué cree que el dibujo de Milton desapareció detrás de la puerta. Finalmente, para las situaciones reincidentes podría preguntarse qué le podría suceder al videojuego si Milton no hubiera sido incluido por los desarrolladores o qué cambiaría en términos de la repetición discursiva sobre personaje.

\section{Conclusiones}

Llevar el videojuego al aula implica muchas consideraciones respecto de su potencial como un recurso didáctico frente a la competencia lectora. La postulación de categorías narrativoficcionales es una ruta para organizar su aplicación en procesos de enseñanza-aprendizaje, en la medida en que ofrece una base de análisis que acerca al videojuego al concepto de un texto multimodal. A partir de estas categorías, entender los objetivos de lectura como conductores de los esquemas de comprensión puede ayudar a delimitar el uso del videojuego dentro del aula y evitar tomarlo solo como una entretención. Es precisamente la interactividad del videojuego, su respuesta inmediata y multiplicidad discursiva lo que podría fortalecer una comprensión profunda y multimodal para el estudiante, puesto que cada estímulo podría

Volumen 2. Número 2. Julio - Diciembre 2022 
restringirse en un solo objetivo de lectura, algo que un libro de texto difícilmente podría alcanzar. La interactividad constante e inmediata del videojuego con su usuario podría ayudar a entretener mientras se educa subrepticiamente, a través del mismo gameworld, gamestructure y gameplay.

El conjunto de categorías seleccionadas para esta investigación puede llevarse a una gran variedad de juegos y jugadores posibles. Por ejemplo, sería valioso evaluar el papel que las distintas categorías de análisis del videojuego tendrían en juegos hechos para la realidad virtual, o en las distintas experiencias interactivas que no tienen necesariamente un gamestructure. También, podría ser interesante determinar cómo la experiencia narrativa y ficcional cambia con un receptor que tenga dificultades auditivas o kinestésicas, con el fin de poder llevar a los terrenos de la evaluación esas implicaciones particulares. En última instancia, podría usarse el ejemplo trabajado para estructurar una práctica de aula real, de manera que la multiplicidad de dimensiones y ventajas pedagógicas puedan materializarse en un recurso didáctico completo para la enseñanza y evaluación de la competencia lectora.

La capacidad del videojuego de hacer que el jugador viva experiencias narrativas visuales, kinestésicas y textuales está influida por procesos lectores a los que se someta el receptor para comprender, de manera que estas competencias no solo estarían restringidas al videojuego, sino también a la lectura de textos, películas, contextos, situaciones, sentimientos, etc. El videojuego es un gran punto de fuga, el cual parte de procesos lectores pero que podrían desembocar en distintas áreas o dimensiones valiosas para el ser humano. De manera que leer la duda, la preocupación o la tristeza sugerida de un personaje del videojuego puede fortalecer en cierta medida la otredad, como un fundamento de nuestro estar en el mundo. Identificarse con un personaje, personajes o situaciones del videojuego podrían devolver al receptor "nuevos significados e identificaciones existenciales" (Contursi y Ferro, 2000, p.59). Un videojuego podría ser, incluso, el primer mecanismo que tenga un niño o niña contemporáneo para encontrar su sentido entre las cosas, sabiéndose uno entre otros muchos. Por tanto, el videojuego ayuda a su lector a que pueda entender el gameworld y gamestructure, a sí mismo, puede promover su comprensión como ser humano y su situación en la historia y del mundo 
como multiplicidad de matices filosóficos, antropológicos, sociológicos, etc., por medio de la lectura.

En este sentido, el videojuego también podría entrar en consideración para la construcción de enfoques didácticos que tengan en cuenta un rol del docente que comprenda tanto las implicaciones del videojuego en el aula como las posibilidades que este tiene en cuanto a la invención de su jugador/estudiante. Enfoques didácticos que comprendan que la educación en la actualidad tiende a la intertextualidad, hipertextualidad y multimodalidad que ofrecen los medios tecnológicos, que también son discursivos, como la televisión, el internet o los videojuegos. Una comprensión de la interactividad en la actualidad como algo fundamental que no debe ponerse del lado de lo inútil o trivial de los medios que la utilizan. De manera que el videojuego pueda quitar el velo que la historia le ha impuesto, necesaria pero incorrectamente, como un medio de entretención más, para poder así aprovecharlo en cada una de sus limitaciones y libertades implícitas.

\section{Referencias}

Alliaud, A. (2006). Experiencia, Narración y Formación Docente. Educação \& Realidade, 31(1),7-22. ISSN: 0100-3143. https://www.redalyc.org/articulo.oa?id=3172/317227043011

Aranda, D., y Sánchez, J. (2009) Algunas claves para entender los videojuegos. En Aranda, D., y Sánchez, J. (Compiladores). Aprovecha el tiempo y juega, algunas claves para entender los videojuegos, pp.7 - 37. Barcelona, España. Editorial UOCpress.

Cabañes, E. (2012). Del juego simbólico al videojuego: la evolución de los espacios de producción simbólica. Videojuegos y juventud. Revista de estudios de juventud. (98), pp.61 77. https://issuu.com/injuve/docs/revista98

Contursi, M., y Ferro, F. (2000). La narración, usos y teorías. Bogotá, Colombia. Grupo Editorial Norma. 
Dolezel, L. (1988). Mímesis y mundos posibles. En Garrido, A (compilador). Teorías de la ficción literaria. (pp.69 - 95). Madrid, España. Editorial Arco Libros.

Eco, U. (1962). Obra abierta. Barcelona, España. Editorial Planeta - Agostini.

Eco, U. (1987). Los límites de la interpretación. Barcelona, España. Editorial Lumen.

Eco, U. (1994). Seis paseos por los bosques narrativos. Barcelona, España. Editorial Lumen.

Fabricatore, Carlo. (2000) Learning and Videogames: An Unexploited Synergy. In: 2000 Annual Convention of the Association for Educational Communications and Technology (AECT). In Search of the Meaning of Learning. http://eprints.hud.ac.uk/id/eprint/28000/

Frasca, G. (2009). Juego, videojuego y creación de sentido. Una introducción. Comunicación: revista Internacional de Comunicación Audiovisual, Publicidad y Estudios Culturales, 1 (7), $37-44$.

Fuenmayor, G., y Villasmil, Y. (2008). La percepción, la atención y la memoria como procesos cognitivos utilizados para la comprensión textual. Revista de Artes y Humanidades UNICA, 9(22),187-202.[fecha de Consulta 21 de Marzo de 2021]. ISSN: 1317-102X. https://www.redalyc.org/articulo.oa?id=170118859011

Fundación Promigas. (2013). Comprensión y producción textual. Elibro. http://www.fundacionpromigas.org.co/es/Biblioteca/Documents/Libros/Comprension\%20y \%20Producci\%C3\%B3n\%20Textual\%20-\%20Version\%20Digital.pdf

Garrido, A. (1997). Teorías de la ficción literaria: Los paradigmas. En Garrido, A (compilador). Teorías de la ficción literaria. (pp.11 - 43). Madrid, España. Editorial Arco Libros. 
Gómez, J. (23 de abril de 2021). ¿Qué tanto se lee en Colombia?. Confidencial Colombia. https://confidencialcolombia.com/placeres/que-tanto-se-lee-en-colombia/2021/04/23/

Harshaw, B. (1984). Ficcionalidad y campos de referencia. En Garrido, A (compilador). Teorías de la ficción literaria. (pp.123 - 159). Madrid, España. Editorial Arco Libros.

Huizinga, J. (1938). Homo Ludens. Alianza Editorial. Madrid, España.

Instituto Colombiano para la Evaluación de la Educación (2020). Informe nacional de

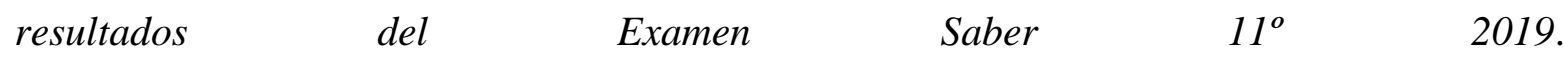
https://www.icfes.gov.co/documents/20143/1711757/Informe+nacional+de+resultados+Sab er+11-2019.pdf/01cca382-1f24-aefd-a3ef-0d04d2e6108d?version=1.0\&t=1608776793757

Koenitz, H. (2018). Narrative in Video Games. Encyclopedia of Computer Graphics and Games. https://10.1007/978-3-319-08234-9_154-1

López, C. (2013). El videojuego como práctica discursiva contemporánea. Pokemón y la naturalización de la realidad social neoliberal. [Tesis doctoral]. https://ddd.uab.cat/pub/tesis/2014/hdl_10803_130793/clr1de1.pdf

Organización para la Cooperación y el Desarrollo Económicos (2019). El Programa para la Evaluación Internacional de Alumnos (PISA) 2018. Country Note, OECD. https://www.oecd.org/pisa/publications/PISA2018_CN_COL_ESP.pdf

Ramírez, M. (30 de septiembre de 2020). Cuarentena cambió los hábitos de lectura de los colombianos, pero el lector habitual se consolidó. La República. https://www.larepublica.co/ocio/la-cuarentena-cambio-los-habitos-de-lectura-de-loscolombianos-y-cautivo-a-unos-pocos-3067114

Saer, J. (1997). El concepto de ficción. Buenos Aires, Argentina. Editorial Seix Barral. 
Solé, I. (1992). Estrategias de lectura. Barcelona, España. Editorial Graó.

Todorov, T. (1970). Las categorías del relato literario. En Barthes, R. El análisis estructural del relato. (pp.155 - 193). República Argentina. Editorial Tiempo Contemporáneo.

Vargas, L. (3 de octubre de 2020). Desde el inicio de la pandemia el número de jugadores virtuales en Colombia incrementó 16\%. La República. https://www.larepublica.co/interneteconomy/desde-el-inicio-de-la-pandemia-el-numero-de-jugadores-virtuales-en-colombiaincremento-16-3068818

Wolf, M., y Perron, B. (2005). Introducción a la teoría del videojuego. Revista de comunicación audiovisual. (4) pp.1-27. https://www.raco.cat/index.php/Formats/article/download/257329/344420

Woolfolk, A. (2010). Psicología educativa. Juárez, México. Editorial Pearson Educación. 
REVISTA INTERNACIONAL DE PEDAGOGÍA E INNOVACIÓN EDUCATIVA|

Volumen 2. Número 2. Julio - Diciembre 2022 ISSN: 2745-0341 (En línea) 